\title{
Salinity-Dependent Adhesion Response Properties of Aluminosilicate (K-Feldspar) Surfaces
}

\author{
B. Lorenz, ${ }^{* \dagger \oplus}$ M. Ceccato, ${ }^{\dagger}$ M. P. Andersson, ${ }^{\dagger}$ S. Dobberschütz, ${ }^{\dagger}$ J. D. Rodriguez-Blanco, ${ }^{\dagger}$, \\ K. N. Dalby, ${ }^{\dagger}$ T. Hassenkam, ${ }^{*}{ }^{\dagger}$ and S. L. S. Stipp ${ }^{\dagger}$ \\ ${ }^{\dagger}$ Nano-Science Center, Department of Chemistry, University of Copenhagen, Copenhagen 2100, Denmark \\ 'Department of Geology, Trinity College Dublin, Dublin 2, Ireland
}

\section{Supporting Information}

ABSTRACT: Flooding sandstone oil reservoirs with low salinity water can lead to a significant increase in oil recovery, a phenomenon called "the low salinity effect". Although there are many factors that contribute to this response, the surface tension on the pore walls is an important one. Sandstone is composed predominantly of quartz with some clay, but feldspar grains are often also present. While the wettability of quartz and clay surfaces has been thoroughly investigated, little is known about the adhesion properties of feldspar. We explored the interaction of model oil compounds, molecules that terminate with carboxyl, $-\mathrm{COO}(\mathrm{H})$, and alkyl, $-\mathrm{CH}_{3}$, with freshly cleaved, museum quality perthitic microcline, $\mathrm{K}_{x} \mathrm{Na}_{(1-x)} \mathrm{AlSi}_{3} \mathrm{O}_{8}$, a $\mathrm{K}$-feldspar. Microcline is a member of the orthoclase family, a type of feldspar that weathers more slowly than the plagioclase series, and thus is more likely to be preserved in well sorted sandstone. Adhesion forces, measured with the chemical force mapping (CFM) mode of atomic force microscopy (AFM), showed a low salinity effect on the fresh feldspar surfaces. Adhesion force, measured with $-\mathrm{COO}(\mathrm{H})$-functionalized tips, was $60 \%$ lower in artificial low salinity seawater (LS, 1500 ppm total dissolved solids) than in the high salinity solution, artificial seawater (HS, ASW, $\sim 35600 \mathrm{ppm}$ ). Adhesion with the $-\mathrm{CH}_{3}$ tips was as much as $30 \%$ lower in LS than in HS. Density functional theory calculations indicated that the low salinity response resulted from expansion of the electric double layer and that contributions from cation bridging are of less importance. Adventitious carbon, that is, organic material that is inherent on all mineral surfaces exposed to air or water, can enhance nonpolar component adhesion by serving as anchor points.

\section{INTRODUCTION}

When sandstone reservoirs are flooded with low salinity seawater, oil recovery can be increased by as much as $\sim 40 \%$ over what can be produced using traditional flooding with seawater, a phenomenon called the "low salinity effect". ${ }^{1-5}$ Even though this technology is successfully applied in the field, there is still debate about the factors that control oil release under such conditions. ${ }^{6}$ Producing more oil from existing reservoirs offers economic and environmental benefits, because it can use existing infrastructure and decreases the need to develop new fields, such as in the Arctic, where risks to the environment are high. To further increase well productivity, it is essential to understand how oil binds to pore surfaces and to learn which parameters control the processes at the molecular scale. Field experiments are costly and time-consuming, while laboratory studies can provide considerable insight at relatively low costs.

During the past years, the effect of low salinity on oil recovery has been investigated by several groups, in the laboratory ${ }^{4,7}$ and at field scale. ${ }^{2,5,8}$ At both scales, the low salinity effect occurs when the total amount of dissolved salts is below a limit of $\sim 5000 \mathrm{ppm} .{ }^{9,10}$ Detailed laboratory studies on model surfaces, such as oxidized silicon wafers ${ }^{11}$ or mica ${ }^{11,12}$ as well as on natural quartz surfaces from outcrop and solvent cleaned reservoir sandstone, ${ }^{9,13}$ indicate that the low salinity effect is also linked to a salinity-dependent wettability conversion on the pore surfaces, making them mostly more hydrophilic, that is, water wet. ${ }^{14,15}$ The idea that wettability plays a role in oil release was also confirmed at field scale, ${ }^{16}$ but the underlying chemical mechanisms that control this wettability shift remain debated. ${ }^{17}$

Several theories have been proposed to explain the process, ${ }^{8,14,18}$ with studies mainly focused on quartz and clay. The general consensus is that, in addition to a change of salinity, ${ }^{1,4}$ the wettability of mineral surfaces is also affected by factors ${ }^{6}$ such as the amount of multivalent ions present at the mineral-oil-water interface, ${ }^{7,19,20}$ the amount of polar components in the oil, ${ }^{4,14}$ and the presence of clay minerals. ${ }^{4,8}$ However, it is possible that the clay minerals and quartz might not solely be responsible for the low salinity effect because aluminosilicates, mainly the feldspar minerals, can also be present in significant quantities in sandstones, as much as $30 \%$ by mass, depending on the type of reservoir. Despite their abundance, little is known about their role in the low salinity effect. There is only one study on Ca-feldspar in sandstone reservoir core material and outcrop samples where the aim was to determine the contribution of the feldspar. ${ }^{21}$ Results indicated that, depending on the salinity of the formation water, Ca-feldspar could change the initial wetting condition of the reservoir by changing the formation water $\mathrm{pH}$ so the feldspar could promote low salinity enhanced oil recovery by locally changing $\mathrm{pH}$ at clay surfaces when salinity decreased.

Received: November 10, 2016

Revised: $\quad$ March 23, 2017

Published: March 27, 2017 
Previous work has also demonstrated that organic material, present in the original seawater when the sediments accumulated or in the pore fluids, adsorbs on the mineral grain surfaces and influences their adhesion properties. ${ }^{22}$ This inherent organic material, which is present on all mineral surfaces from long before hydrocarbons infiltrate a porous formation, controls net surface tension. Adventitious organic material is also observed on freshly fractured model surfaces, on polished surfaces, and even on surfaces freshly cleaned using UV-ozone treatment. ${ }^{11}$ This adsorbed carbon contamination comes spontaneously from the air or solution in contact with the solid phase and affects the adsorption properties of the pore surfaces. Thus, the history of the sediment has a strong effect on its wetting properties.

In this study, we investigated a sample of K-feldspar, a member of the orthoclase family, a type of feldspar that weathers more slowly than members of the plagioclase series, and thus is more likely to be preserved in well sorted sandstone. We used atomic force microscopy (AFM) in chemical force mapping (CFM) mode, ${ }^{23-25}$ to map adhesion forces as a function of solution composition. We cleaved fresh fragments from a museum specimen of perthitic microcline, $\mathrm{K}_{x} \mathrm{Na}_{(1-x)} \mathrm{AlSi}_{3} \mathrm{O}_{8}$, and we measured adhesion using functionalized AFM tips that had terminations of carboxyl, $-\mathrm{COO}(\mathrm{H})$, and methyl, $-\mathrm{CH}_{3}$. The interaction between these common functional groups and the mineral surface was monitored in the presence of solutions, artificial seawater (ASW; $35600 \mathrm{ppm}$ ), which we refer to as high salinity solution (HS), and low salinity solution (LS; $1500 \mathrm{ppm}$ ), which is simply diluted HS. We also tested the effect of adventitious compounds on adhesion. Finally, we used density functional theory (DFT) to evaluate how the presence of cation bridges between the tip and the surface would affect the adhesion properties.

\section{EXPERIMENTAL DETAILS}

Sample Origin and Preparation. All samples used in this study came from a $1 \times 1 \times 3 \mathrm{~cm}^{3}$ pale pink microcline crystal that had been collected from a pegmatite in Bancroft, Ontario, Canada (Figure 1a). The mineral was identified as perthitic microcline by $\mathrm{X}$-ray diffraction

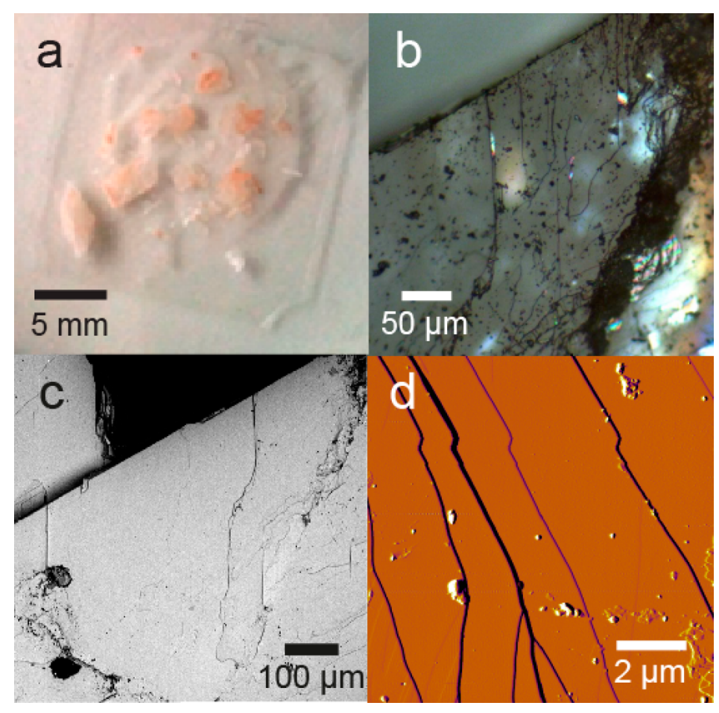

Figure 1. (a) Perthitic microcline cleavage fragments attached to a glass cover clip with epoxy, (b) view of one particle using reflective light microscopy, (c) a backscattered electron image of a cleavage plane, and (d) an AFM amplitude image of a freshly cleaved surface.
(XRD), and its surface composition was determined by X-ray photoelectron spectroscopy (XPS). Fragments, ranging in size from $1 \times 1$ to $5 \times 5 \mathrm{~mm}^{2}$, were cleaved from the crystal with a scalpel. The fragments were attached to a glass slide using a thin layer of epoxy resin (EPON Resin 1002F, Momentive Specialty Chemicals Inc., $\mathrm{NY}) .{ }^{13}$ The slide was then blown with a jet of pure nitrogen to remove small chips that were not securely attached. Surfaces were not treated further prior to the experiments. A conventional light microscope was used to verify that the epoxy had not covered the surfaces and to identify suitable target areas on large, flat terraces that could be accessed with an AFM tip.

Scanning Electron Microscopy (SEM) and Electron Dispersive X-ray Spectroscopy (EDXS). SEM and EDXS were used to estimate the bulk composition of the feldspar. We used an FEI Quanta 3D field emission gun SEM, with a voltage contrast back scattered electron detector, at an accelerating voltage of $10 \mathrm{keV}$. Sample coating was not necessary because we worked in low vacuum $\left(60 \mathrm{~Pa}\right.$ of $\left.\mathrm{H}_{2} \mathrm{O}\right)$. EDXS spectra and maps were collected with a $20 \mathrm{~mm}^{2}$ Oxford Instruments X-Max silicon drift detector.

X-ray Diffraction (XRD). For XRD analysis, $\sim 200 \mathrm{mg}$ of the sample was ground into a fine powder using an agate mortar and pestle and passed through a $50 \mu \mathrm{m}$ sieve to minimize the effects of preferred orientation. We determined mineral identity using conventional XRD patterns collected with a Bruker D8 Discover (Co K $\alpha 1,1.7902 \AA ; 2 \theta$ range 5-90; $0.01^{\circ} /$ step and $\left.1 \mathrm{~s} / \mathrm{step}\right)$. Data were compared to standard mineral files compiled in the PDF2 database (ICDD PDF-2 Powder Diffraction File Database), using the software code EVA. Structural parameters were estimated from diffraction patterns with pattern matching refinement of the crystalline phases using the Rietveld refinement software TOPAS. ${ }^{26,27}$

X-ray Photoelectron Spectroscopy (XPS). The element composition of the surface $(10 \mathrm{~nm})$ and the amount of organic material on the surface were determined using XPS. Measurements were made on $\sim 3 \mathrm{~mm} \times 5 \mathrm{~mm}$ particles that had been exposed to air or air and artificial seawater. We used a Kratos Axis Ultra ${ }^{\text {DLD }}$ instrument operated with a monochromatic $\mathrm{Al}_{\mathrm{K} \alpha} \mathrm{X}$-ray source $(h \nu=$ $1486.6 \mathrm{eV}$ ) at a power of $150 \mathrm{~W}$. Survey scans were acquired in the $0-$ $1355 \mathrm{eV}$ range at a pass energy of $160 \mathrm{eV}$ and a step size of $0.5 \mathrm{eV}$. High-resolution scans of the $\mathrm{C} 1 \mathrm{~s}$ region $(278-300 \mathrm{eV})$ were acquired at a pass energy of $10 \mathrm{eV}$ and a step size of $0.1 \mathrm{eV}$. The pressure in the main chamber during the analysis was in the $10^{-9}$ Torr range. The XPS data were processed using the CasaXPS software. Atomic surface concentrations were determined by fitting the core level spectra using Gaussian-Lorentzian line shapes and a Shirley background correction. The value reported represents the average of at least two measurements on two different spots. The absolute energy scale was calibrated to the adventitious carbon $\mathrm{C} 1 \mathrm{~s}$ peak of $285.0 \mathrm{eV} .^{28}$ The measurements were done using a spot size of $0.21 \mathrm{~mm}^{2}$. We estimated the carbon layer thickness using the Beer-Lambert equation, and calculations of the inelastic mean free path, $\lambda$, were performed using the predictive TPP-2M equation, provided in the NIST database.

Atomic Force Microscopy (AFM) Imaging. Intermittent contact mode imaging with OMCL-AC240 cantilevers (nominal spring constant, $2 \mathrm{~N} / \mathrm{m}$; resonance frequency, $70 \mathrm{kHz}$ ) and a conventional MFP3D (Asylum Research, Santa Barbara, CA) was performed to extract topographic information from the surfaces. We used a set point corresponding to $\sim 80 \mathrm{~nm}$ oscillation amplitude, with a free amplitude of $\sim 100 \mathrm{~nm}$.

Procedure. To mimic reservoir conditions, chemical force mapping was performed in artificial seawater (HS; $35600 \mathrm{ppm}$ of total dissolved solids, consisting of $478 \mathrm{mM} \mathrm{NaCl}, 57 \mathrm{mM} \mathrm{MgCl}_{2}, 12$ $\mathrm{mM} \mathrm{CaCl} 2$, and $12 \mathrm{mM} \mathrm{KCl})$ and LS $(\sim 1500 \mathrm{ppm})$, which was made by diluting $\mathrm{HS}$ with ultrapure deionized water by a factor of $\sim 24$. It consisted of $20 \mathrm{mM} \mathrm{NaCl}, 2 \mathrm{mM} \mathrm{MgCl}, 0.5 \mathrm{mM} \mathrm{CaCl}_{2}$, and $0.5 \mathrm{mM}$ $\mathrm{KCl}$. Salts were ACS Reagent grade or better ( $\geq 99 \%)$. For both solutions, $\mathrm{pH}$ was adjusted to 5.5 using $\mathrm{HCl}$ or $\mathrm{NaOH}$. The solutions were filtered through cellulose acetate syringe filters $(0.02 \mu \mathrm{m}$ pore size). The glass slide with the samples attached was clamped in a freshly ozone cleaned PEEK (polyether ether ketone) AFM fluid cell. Samples that had previously been analyzed with AFM or SEM were 
excluded from the CFM measurements to avoid the risk of surface change before analysis. Biolever cantilevers (BL-RC-150VB, Olympus) were functionalized with self-assembled thiol monolayers (SAM), as described by others, ${ }^{23,29,30}$ exposing them for at least $24 \mathrm{~h}$, at room temperature, to a $1-3 \mathrm{mM}$ ethanolic solution of hexadecanethiol, for the $-\mathrm{CH}_{3}$ terminated tip, or 1-mercaptohexadecanoic acid, for the $-\mathrm{COO}(\mathrm{H})$ terminated tip. They were rinsed with ultrapure ethanol just prior to use.

Chemical Force Mapping (CFM). We used the Asylum Research MFP3D for force mapping, with a cantilever that had a nominal spring constant of $6 \mathrm{pN} / \mathrm{nm}$. The functionalized tip and sample were mounted in the fluid cell, and $3 \mathrm{~mL}$ of high salinity solution was injected. The system was equilibrated and calibrated using the thermal noise method. ${ }^{31,32}$ Calibrated spring constants ranged from 6.5 to 9.1 $\mathrm{pN} / \mathrm{nm}$. All measurements were carried out at room temperature. An area of $(5 \times 5) \mu \mathrm{m}^{2}$ was probed by collecting $(50 \times 50)$ separate force-distance curves (Figure $2 \mathrm{a}$ ) while the tip was rastered over the
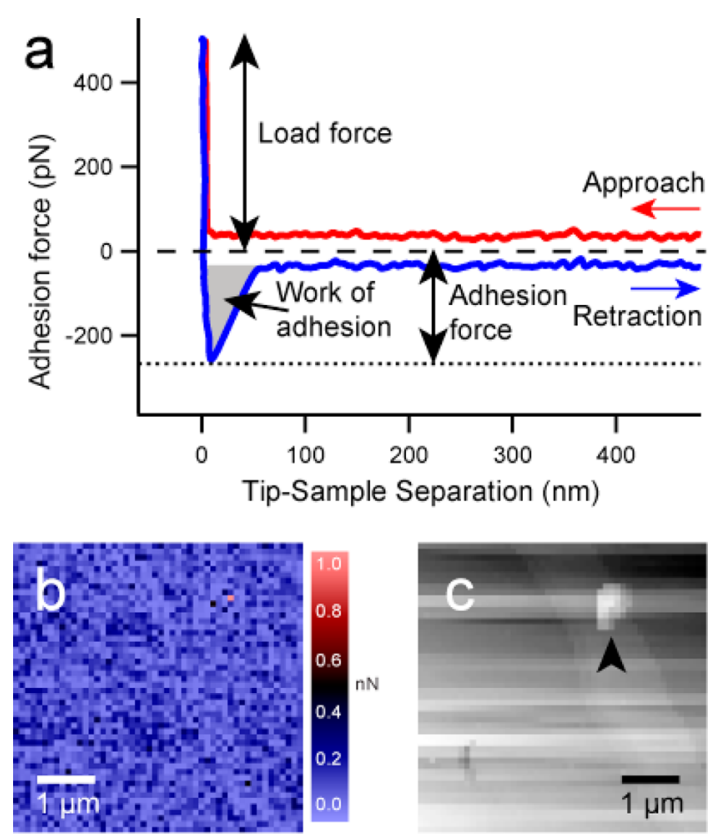

Figure 2. Chemical force mapping. (a) A typical force-distance curve resulting from an approach-retraction cycle using a $-\mathrm{COO}(\mathrm{H})$ tip on a freshly cleaved K-feldspar surface. The tip approaches the surface (red curve) until a load force of $500 \mathrm{pN}$ is exerted by the tip on the surface. After being in contact for $0.1 \mathrm{~s}$, the tip is retracted from the surface (blue curve). The hysteresis between the approach and retract curves is a consequence of hydrodynamic drag in the solution. It is corrected for by setting a new baseline (dashed line) at one-half the distance between the two. Adhesion force, which is equivalent to the force acting on the cantilever at its maximum deflection (dotted line), is used to construct adhesion maps, such as (b), with force ranging from a few tens of $\mathrm{pN}$ (light blue) to $1 \mathrm{nN}$ (pink). Height information can be extracted from the force-distance curve as well, providing simultaneous data for constructing a topography map, such as (c), for identifying characteristic features that serve as markers, such as at the arrow, to allow the same area to be mapped in subsequent scans.

surface for $\sim 18 \mathrm{~min}$. Force-distance curves were recorded with $\sim 16$ $\mu \mathrm{m} / \mathrm{s}$ tip approach and retraction velocity, $500 \mathrm{pN}$ force load, $0.1 \mathrm{~s}$ dwell time on the surface, and $2 \mu \mathrm{m}$ tip-sample distance after tip retraction.

Movement of the cantilever through the fluid causes hydrodynamic drag, which results in hysteresis ranging from 60 to $100 \mathrm{pN}$ between approach and retract curves (Figure 2a). The data were corrected by fitting the approach and retract curves with lines and setting the baseline at one-half the distance between them. We assume the cantilever is deflected by the same amount relative to its equilibrium position, whether it is approaching or retracting, and that the effect of salinity on deflection is negligible. Because we are interested in the change in adhesion, not the absolute adhesion, uncertainties associated with these assumptions would be negligible.

Each adhesion map, such as Figure $2 b$, was constructed from the 2500 adhesion force data points. The height maps, such as Figure $2 c$, were built from the sample height from each of the 2500 curves. In height maps, low areas on the sample are represented by dark gray; light colors identify higher structures. Characteristic features on the surface, such as the one marked by the arrow in the height map, Figure $2 c$, were used as reference features to ensure that consecutive adhesion maps were recorded over the same sample site. They served to evaluate the extent of drift, which is observed as an apparent relative shift between sample and tip, and were used to locate the same sample site again after replacing the cantilever or exchanging solutions. These reference features were chosen so that they were recognizable but with limited height, to minimize tip edge artifacts. When extensive drift (200-300 nm) was observed, we compensated by repositioning the sample before the next scan. When drift was smaller $(<100 \mathrm{~nm})$, we accounted for it in the data analysis by selecting subsets of the image over consistent areas, identified with the reference features.

In Figure 2b, light blue corresponds to very low adhesion force, and pink represents the highest force. The contrast of the adhesion maps was optimized by setting the upper force threshold to $1 \mathrm{nN}$. None of the extracted adhesion force values reached this threshold.

Salinity-Dependent Measurements. To extract information about the adhesion between the K-feldspar surface and the $-\mathrm{CH}_{3}$ and $-\mathrm{COO}(\mathrm{H})$ tips, we used two types of measurements: (i) Three different sample sites were all probed, first in HS, then the solution was exchanged and each of the same sites was imaged in LS. The full sequence was performed identically, with a $-\mathrm{COO}(\mathrm{H})$ tip and a $-\mathrm{CH}_{3}$ tip. In measurement type (ii), a specific site was probed in alternating HS and LS, through 4 or 5 exchanges, so the total sequence was HS-LS-HS-LS-HS or HS-LS-HS-LS-HS-LS. For solution exchanges, we removed $1.5 \mathrm{~mL}$ of the $3 \mathrm{~mL}$ initial solution from the fluid cell and injected $1.5 \mathrm{~mL}$ of the new solution, which was at the same temperature as the fluid cell, through eight cycles. Adhesion force maps were generally recorded from bottom to top, and the time passed between data collection was kept as short as possible. It typically took 5 to $15 \mathrm{~min}$ to exchange the liquid, reposition, and begin scanning again.

Contact Angle Data. Wetting angle was determined from the work of adhesion between the tip and the sample, using the YoungDupré equation for an oil droplet interacting with a solid surface in a water phase:

$$
\gamma_{\mathrm{OW}}(1-\cos \theta)=\Delta W_{\mathrm{MOW}}
$$

where $\gamma_{\mathrm{OW}}$ represents the interfacial tension between the oil and the water phase, $\theta$ represents the contact angle, and $W_{\text {MOW }}$ is the adhesion work per unit surface area. ${ }^{12,25,33}$ In our case, $\gamma_{\text {OW }}$ represents the surface tension between hydrophobic molecules at the apex of the AFM tip with the surrounding aqueous phase, and we assumed this to be $50 \mathrm{mN} / \mathrm{m}$, similar to the value for a hexadecyl/water interface. ${ }^{34,35}$ We determined contact angle using two approaches: (i) contact angle determined from the interaction that the apex of a $-\mathrm{CH}_{3}$ functionalized AFM tip would make in contact with the area mapped (i.e., $5 \times 5 \mu \mathrm{m}^{2}$ ) and (ii) the average of the set of contact angles that could be determined from the force-distance curves made at each pixel of the scanned area. These individual measurements were used to make contact angle maps.

For method 1, we used the total work of adhesion averaged over the whole map, normalized by the total interaction area. For method 2, we used the normalized adhesion work for each force-distance curve. The adhesion work was determined for each force curve by integrating over the gray area depicted in Figure 2a. The surface area was normalized using a contact area of $365 \mathrm{~nm}^{2}$ and a tip radius of $\sim 22 \mathrm{~nm} .{ }^{25}$ Using this approach, we could estimate the wettability distribution over the surface, which is a much higher resolution than anything that has been possible using classical contact angle measurements. 
a

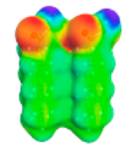

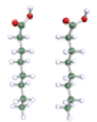

prot.

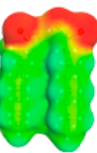

200
20
0
0

singly
deprot.

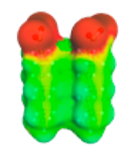

.
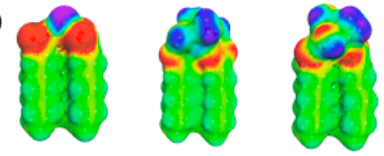

政
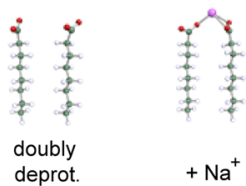

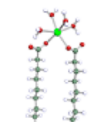

doubly deprot.

$+\mathrm{Ca}\left(\mathrm{H}_{2} \mathrm{O}\right)_{4}^{2+}+\mathrm{Mg}\left(\mathrm{H}_{2} \mathrm{O}\right)_{4}^{2+}$
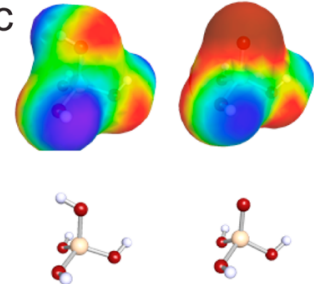

$\mathrm{Si}(\mathrm{OH}) 4$

$\mathrm{Si}(\mathrm{OH})_{3} \mathrm{O}^{-}$

Figure 3. COSMO surfaces (top row) and molecular structures (bottom row) for (a) the protonated, singly deprotonated, and doubly deprotonated octanoate dimer, (b) the doubly deprotonated octanoate dimer with adsorbed $\mathrm{Na}^{+}, \mathrm{Ca}\left(\mathrm{H}_{2} \mathrm{O}\right)_{4}{ }_{4}^{2+}$, and $\mathrm{Mg}\left(\mathrm{H}_{2} \mathrm{O}\right)_{4}{ }^{2+}$, and (c) models for a unit from the K-feldspar surface: neutral $\mathrm{Si}(\mathrm{OH})_{4}$ and negatively charged $\mathrm{Si}(\mathrm{OH})_{3} \mathrm{O}^{-}$. COSMO surfaces are screening charge surfaces; the colors represent neutral (green), negative charge (blue), and positive charge (red). The atoms under the colored areas have the opposite charge.

Density Functional Theory (DFT) Calculations. All DFT calculations were performed with the TURBOMOLE program ${ }^{36}$ v6.5, using the Becke-Perdew (BP) functional, ${ }^{37,38}$ the triple- $\zeta$ valence plus polarization (TZVP) basis set, ${ }^{39}$ and the COSMO implicit solvent model ${ }^{40}$ with infinite dielectric constant. The COSMOtherm program, with the parametrization version BP TZVP C30 1301, was used for all COSMO-RS calculations that were performed at $298 \mathrm{~K}^{41,42} \mathrm{We}$ modeled the $-\mathrm{COO}(\mathrm{H})$ tip using a dimer of octanoate, where we froze the six carbon atoms furthest from the $-\mathrm{COO}(\mathrm{H})$ during the optimization so we could predict the average $-\mathrm{COO}(\mathrm{H})-\mathrm{COO}(\mathrm{H})$ distances that one could expect in a self-assembled monolayer (SAM) on gold. This was determined to be $\sim 5 \AA^{43}$ The $\mathrm{p} K_{\mathrm{a}}$ values for the first and second protonation of the dimer were estimated using COSMOtherm. The adsorption energy for ions to the $-\mathrm{COO}(\mathrm{H})$ tip was determined in the reaction panel of COSMOtherm, which calculates the free energy of a reaction in solution (excluding the effect of the partition functions). Solvation at the feldspar surface was estimated using the flatsurf panel in COSMOtherm, with $50 \mathrm{mN} / \mathrm{m}$ as the interfacial tension (details are presented in Tables S1-S3). The flatsurf module calculates the free energy of transferring a molecule from a bulk solvent to an interface between two solvents. We considered the following reactions for the singly deprotonated dimer $\left(\mathrm{R}=\mathrm{C}_{7} \mathrm{H}_{16}\right)$ in reactions Ia and $\mathrm{Ib}$ :

Reaction with $\left[\mathrm{Na}\left(\mathrm{H}_{2} \mathrm{O}\right)_{2}\right]^{+}$:

$$
\begin{gathered}
{\left[\mathrm{Na}\left(\mathrm{H}_{2} \mathrm{O}\right)_{2}\right]^{+}(\mathrm{aq})+[(\mathrm{RCOOH}) /(\mathrm{RCOO})]^{-}(\text {interface }) \rightarrow} \\
2 \mathrm{H}_{2} \mathrm{O}(\mathrm{aq})+(\mathrm{RCOOH}) /(\mathrm{RCOONa})(\text { interface })
\end{gathered}
$$

Reaction with $\left[\mathrm{Ca}\left(\mathrm{H}_{2} \mathrm{O}\right)_{6}\right]^{2+}$ :

$$
\begin{aligned}
& {\left[\mathrm{Ca}\left(\mathrm{H}_{2} \mathrm{O}\right)_{6}\right]^{2+}(\mathrm{aq})+[(\mathrm{RCOOH}) /(\mathrm{RCOO})]^{-}(\text {interface }) \rightarrow} \\
& 2 \mathrm{H}_{2} \mathrm{O}(\mathrm{aq})+\left[(\mathrm{RCOOH}) /\left(\mathrm{RCOO}\left[\mathrm{Ca}\left(\mathrm{H}_{2} \mathrm{O}\right)_{4}\right]\right)\right]^{+}(\text {interface })
\end{aligned}
$$

We considered the following reactions for the doubly deprotonated dimer in reactions IIa and IIb:

Reaction with $\left[\mathrm{Na}\left(\mathrm{H}_{2} \mathrm{O}\right)_{2}\right]^{+}$

$$
\begin{gathered}
{\left[\mathrm{Na}\left(\mathrm{H}_{2} \mathrm{O}\right)_{2}\right]^{+}(\mathrm{aq})+\left[(\mathrm{RCOO})_{2}\right]^{2-}(\text { interface }) \rightarrow} \\
2\left(\mathrm{H}_{2} \mathrm{O}\right)(\mathrm{aq})+\left[(\mathrm{RCOOH})_{2} \mathrm{Na}\right]^{-}(\text {interface })
\end{gathered}
$$

Reaction with $\left[\mathrm{Ca}\left(\mathrm{H}_{2} \mathrm{O}\right)_{6}\right]^{2+}$ :

$$
\begin{aligned}
& {\left[\mathrm{Ca}\left(\mathrm{H}_{2} \mathrm{O}\right)_{6}\right]^{2+}(\mathrm{aq})+\left[(\mathrm{RCOO})_{2}\right]^{2-}(\text { interface }) \rightarrow} \\
& 2\left(\mathrm{H}_{2} \mathrm{O}\right)(\mathrm{aq})+(\mathrm{RCOO})_{2}\left[\mathrm{Ca}\left(\mathrm{H}_{2} \mathrm{O}\right)_{4}\right](\text { interface })
\end{aligned}
$$

The octanoate dimers with and without cations are depicted in Figure 3. The equations for $\mathrm{K}^{+}$were analogous to those for $\mathrm{Na}^{+}$, and the equations for $\mathrm{Mg}^{2+}$ were analogous to those for $\mathrm{Ca}^{2+}$.

For octahedrally coordinated cations, 6 water molecules in the hydration sphere provided reasonable results for hydration energies for $\mathrm{Ca}^{2+}$ and $\mathrm{Mg}^{2+}$. Slightly poorer results, on a relative scale, were achieved for the less strongly hydrated monovalent ions, $\mathrm{Na}^{+}$and $\mathrm{K}^{+}$. ${ }^{44}$ Although the simulations started with six hydration water molecules associated with the monovalent ions adsorbed on the acid dimers, several water molecules were no longer bound to the $\mathrm{Na}^{+}$ions after the geometry optimization. Instead, we used two explicit water molecules to hydrate the monovalent ions because they provided excellent hydration energy values for both $\mathrm{Na}^{+}$and $\mathrm{K}^{+}$(Table S4). Zero point energies as well as translational, rotational, and vibrational partition function contributions were taken into account using standard formulas for molecules in solution.

The molecules in a $-\mathrm{COO}(\mathrm{H})$ SAM are densely packed and covalently bound to the surface so the rotational and translational partition functions were assumed to be 0 for all species including the octanoate dimer. Because most carbon atoms in the dimer were frozen during optimization, two imaginary frequencies were obtained for all octanoate dimer species, which were ignored in the construction of the vibrational partition function. To minimize uncertainties in the vibrational analysis resulting from several small frequencies present in the vibrations, particularly for $\mathrm{Ca}^{2+}$ and $\mathrm{Mg}^{2+}$, we used the average properties for vibrational entropy and zero point energy for the correction terms of these ions. Because the $\mathrm{p} K_{\mathrm{a}}$ for the second deprotonation (6.7; note in Supporting Information) is larger than the $\mathrm{pH}$ of the solutions during the measurements (5.5), we included the energy term, $2.3 R T\left(\mathrm{p} K_{\mathrm{a}}-\mathrm{pH}\right)$ (details presented in note S5), for reaction energies including the doubly deprotonated dimer.

All interactions between the $-\mathrm{COO}(\mathrm{H})$ tip and the K-feldspar surface, in solutions with divalent ions (i.e., $-\mathrm{COO}-\mathrm{M}$, where $\mathrm{M}=$ $\mathrm{Ca}^{2+}$ or $\mathrm{Mg}^{2+}$ ) and without (i.e., the $-\mathrm{COOH}$ dimer alone), were modeled with predicted chemical potentials using COSMOtherm (Table 1). As a model for the fully protonated surface sites, we used $\mathrm{Si}(\mathrm{OH})_{4}$, and for deprotonated surface sites, we used $\mathrm{Si}(\mathrm{OH})_{3} \mathrm{O}^{-} .45,46$ The models for the $-\mathrm{COO}(\mathrm{H})$ tip were the fully deprotonated carboxyl dimer with bound $\mathrm{Ca}^{2+}$ or $\mathrm{Mg}^{2+}$ ions as well as the protonated

Table 1. COSMO-RS Predictions for the Difference in Chemical Potential, $\Delta \Delta \mu(S)$, between a - COO-M Dimer, Where $\mathbf{M}=\mathrm{Ca}^{2+}$ or $\mathrm{Mg}^{2+}$, and a $-\mathrm{COOH}$ Dimer, Which Are Transferred from the Water to the Surface ${ }^{a}$

$\begin{array}{lcc}\text { surface model }(\mathrm{S}) & \Delta \Delta \mu(\mathrm{S}) \mathrm{Ca}^{2+}[\mathrm{kJ} / \mathrm{mol}] & \Delta \Delta \mu(\mathrm{S}) \mathrm{Mg}^{2+}[\mathrm{kJ} / \mathrm{mol}] \\ \mathrm{Si}(\mathrm{OH})_{4} & 0.8 & 0.3 \\ \mathrm{Si}(\mathrm{OH})_{3} \mathrm{O}^{-} & -24.5 & -5.3 \\ \text { benzoic acid } & 9.6 & 9.8 \\ \text { benzoate } & -13.6 & -3.8 \\ \text { octane } & 42.7 & 41.1 \\ \text { benzene } & 35.8 & 36.0 \\ \text { pyridine } & 14.8 & 16.9 \\ \text { thiophene } & 34.4 & 34.7\end{array}$

${ }^{a}$ We considered charged and neutral interfaces of both pure mineral and organic surfaces only for the divalent ions because, according to our predictions, monovalent ions do not bind to the tip. 
acid. Because we were interested in the difference in adhesion between the $-\mathrm{COO}(\mathrm{H})$ tip and the $-\mathrm{CH}_{3}$ tip, we ignored charge effects originating from a surface phase with net negative charge. Instead, we compared the interaction energy of a dimer carrying a divalent ion $(\mathrm{COO}-\mathrm{M}=\mathrm{COO}-\mathrm{Ca}$ or $\mathrm{COO}-\mathrm{Mg}$, Figure $4 \mathrm{a})$ to that of a fully

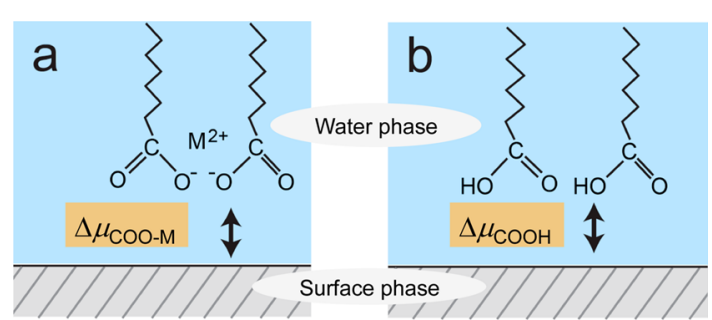

Figure 4. Octanoate dimers interacting with a surface in their (a) deprotonated form, $-\mathrm{COO}-\mathrm{M}$ carrying a divalent ion, $\mathrm{M}^{2+}\left(\mathrm{Ca}^{2+}\right.$ or $\mathrm{Mg}^{2+}$ ), and (b) in their protonated form, $-\mathrm{COOH}$. The difference in chemical potential between the dimers in the water phase, $\mathrm{W}$, and on the surface, $S$, is used to estimate the likelihood of ion bridging between the $-\mathrm{COO}(\mathrm{H})$ tip and the feldspar surface.

protonated dimer $(\mathrm{COOH}$, Figure $4 \mathrm{~b})$, by analyzing the differences in chemical potential, $\mu$, between the dimers interacting with the surface phase, $\mathrm{S}$, and the dimers solvated in the water phase, $\mathrm{W}$.

To this end, we subtracted the difference in chemical potential for the protonated dimers, $\Delta \mu_{\mathrm{COOH}}$, from the difference in potential for the dimers carrying divalent ions, $\Delta \mu_{\mathrm{COO}-\mathrm{M}}$, according to

$$
\begin{aligned}
& \Delta \Delta \mu(\mathrm{S})=\Delta \mu_{\mathrm{COO}-\mathrm{M}}-\Delta \mu_{\mathrm{COOH}} \\
& \quad=\left[\mu_{\mathrm{COO}-\mathrm{M}}(\mathrm{S})-\mu_{\mathrm{COO}-\mathrm{M}}(\mathrm{W})\right]-\left[\mu_{\mathrm{COOH}}(\mathrm{S})-\mu_{\mathrm{COOH}}(\mathrm{W})\right]
\end{aligned}
$$

where $\mu_{\mathrm{COO}-\mathrm{M}}(\mathrm{S})$ and $\mu_{\mathrm{COO}-\mathrm{M}}(\mathrm{W})$ represent the chemical potentials of the COO-M dimer in the two phases, and $\mu_{\mathrm{COOH}}(\mathrm{S})$ and
$\mu_{\mathrm{COOH}}(\mathrm{W})$ are the chemical potentials of the protonated dimers. We used the double difference in chemical potential, $\Delta \Delta \mu$, as a measure of how the surface interaction of the tip decorated with divalent ions compares with a tip without adsorbed ions. Ion bridging is excluded if $\Delta \mu_{\mathrm{COO}-\mathrm{M}} \geq \Delta \mu_{\mathrm{COOH}}$. However, ion bridging takes place if $\Delta \mu_{\mathrm{COO}-\mathrm{M}}<$ $\Delta \mu_{\mathrm{COOH}}$ and then $\Delta \Delta \mu(\mathrm{S})<0$. Contributions from nonterminal parts of the alkane chains cancel using this procedure.

\section{RESULTS AND DISCUSSION}

Sample Characterization. The perthitic microcline was faintly pink (Figure 1a) and translucent in the optical microscope (Figure 1b). XRD patterns, quantified with TOPAS, showed that the sample contained about $81 \%$ microcline (PDF 00-19-0926), 15\% albite (PDF 01-0711150 ), and 4\% quartz (PDF 01-070-7344) (S6). Quantitative analysis of a representative sample by XPS yielded an element surface composition characteristic for potassium feldspar with trace amounts of sodium and calcium, as expected for its mineral composition (Table S7). XRD, XPS, and light microscopy showed evidence for microcline with perthitic texture resulting from exsolution of albite ( $\mathrm{Na}$ plagioclase with $<10 \% \mathrm{Ca}$ ). Albite peaks were clearly identified in the XRD patterns, but EDXS failed to provide convincing evidence of $\mathrm{Ca}$, probably because perthitic intergrowth was minimal in the area analyzed (S8). AFM imaging (Figure 1d) revealed flat cleavage terraces with step heights ranging from 2 to $40 \mathrm{~nm}$. Average root-mean-square roughness was $7.6 \mathrm{~nm}$ over $1 \mu \mathrm{m}^{2}$.

$-\mathrm{COO}(\mathrm{H})$ Interaction with K-Feldspar. Adhesion forces were measured with a $-\mathrm{COO}(\mathrm{H})$ tip from three sites in $\mathrm{HS}$, then the same three sites in LS (Figure 5a and c), where a significant drop in adhesion was observed (Figure $5 b$ and $d$ ). The magnitude of the adhesion force was similar on the three sites and decreased by a similar amount when salinity
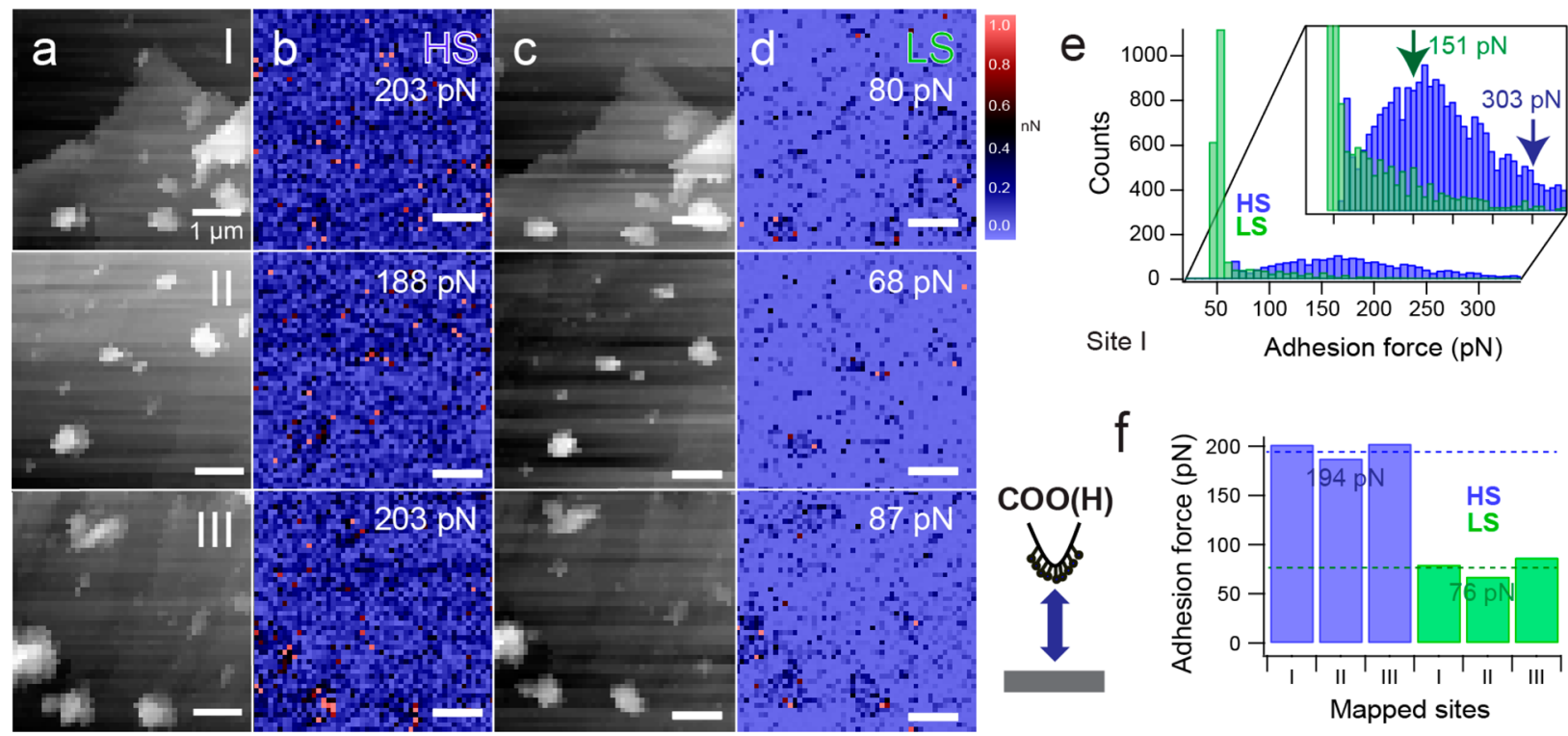

Figure 5. Adhesion response of the $-\mathrm{COO}(\mathrm{H})$ tip to the K-feldspar surface as a function of salinity. (a and c columns) Height maps for three different locations (I, II, III) imaged in HS and LS solutions; (b and d) the corresponding adhesion force maps. For all three areas, average adhesion is higher in HS solutions (dark blue to pink) than in LS (light blue). Scale bars correspond to $1 \mu \mathrm{m}$. (e) Adhesion force distribution for site I, showing response in HS (blue histogram) and LS (green histogram). These are representative for all mapped sites. Force mapping histograms show the distribution of force over the surface. They do not show uncertainty. The range shows that adhesion properties vary considerably over the imaged area. The maps show that, in some cases, nanoparticles have a different adhesion force. The distribution of adhesion force is also different in the two solutions. In the histogram shown, the $90 \%$ quantile is $303 \mathrm{pN}$ for HS (blue arrow) and $151 \mathrm{pN}$ for LS (green arrow). The peaks near $50 \mathrm{pN}$ result from hydrodynamic drag on the cantilever and are an artifact. Bin width is $7 \mathrm{pN}$. (f) Average adhesion force between the $-\mathrm{COO}(\mathrm{H})$ tip and the mineral surface is about $60 \%$ lower in LS than in HS. 
decreased. Figure $5 \mathrm{f}$ shows that the average adhesion was $60 \%$ lower in LS $(76 \mathrm{pN})$ than in HS (194 pN). Within each map, there were areas with significantly different adhesion behavior, which underlines the heterogeneity of the surface composition, even on these freshly cleaved, pure samples. The distributions depicted in Figure 5e show two peaks: a broad one that depends on salinity and a very sharp one at $\sim 50 \mathrm{pN}$, which results from hydrodynamic drag on the cantilever. Correcting for this artifact, that is, excluding the lower $10 \%$ of the measured values, we find adhesion forces ranging up to $300 \mathrm{pN}$ in $\mathrm{HS}$ and $150 \mathrm{pN}$ in LS (Figure 5e). The range of distribution in the histogram is not a measure of uncertainty. It is the variability in force that is sensed by the tip as it rasters over the surface. The variability indicates that the surface is heterogeneous in its interaction with the tip, suggesting very local differences in surface composition.

Following the first set of measurements, we tested for reversibility with similar experiments on a new cleavage fragment (Figure 6). We mapped the same site, starting in

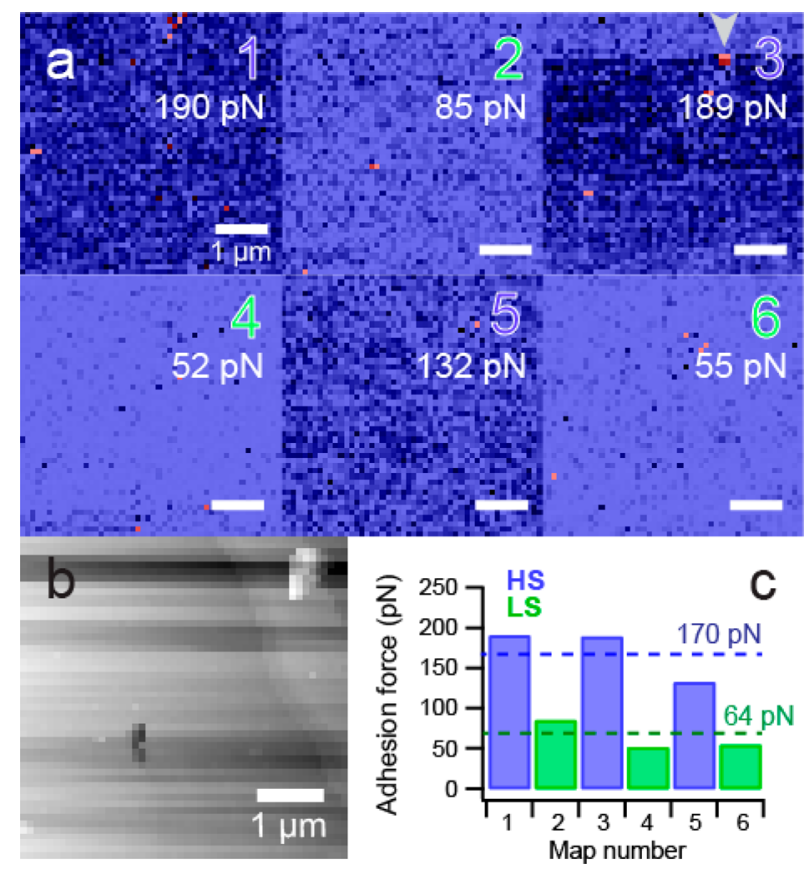

Figure 6. Reversibility of the low salinity effect in an experiment with the $-\mathrm{COO}(\mathrm{H})$ tip on a new site on the K-feldspar. (a) Adhesion maps that were recorded consecutively on site $b$, while the solution was exchanged between HS (blue, maps 1, 3, and 5) and LS (green, maps 2,4 , and 6); (c) average adhesion forces (dashed lines) are $\sim 60 \%$ lower in LS solutions than in HS. Force progressively decreases during the sequence, because of small alterations in the tip surface interactions originating from contaminants in the water. We see a particle on map 3 (arrow) that disappeared in map 4. Color code is as in Figure 5. Scale bars on the maps all correspond to $1 \mu \mathrm{m}$.

HS, and exchanged the solution from high to low salinity several times. The initial average adhesion (Figure $6 \mathrm{a} / 1$ ) is comparable to the average in Figure $5 f$. It decreased by $\sim 62 \%$ during the first exchange to LS (Figure $6 a / 1$ to Figure $6 a / 2$ ). The return to HS (from Figure $6 a / 2$ to $a / 3$ ) caused the adhesion force to return to $99.5 \%$ of its initial value. The subsequent salinity exchanges had a similar effect on adhesion forces, although the overall magnitude decreased slightly, because of small alterations in the tip surface interactions originating from contaminants in the water. We can see an example of this on map 4, where a particle that was on map 3 (arrow) had disappeared. The decrease in adhesion force over the series of experiments was minor relative to the salinity dependent change. To test for reproducibility, we analyzed another particle in the same manner (data shown in S9). The trend was the same. The salinity-dependent change in adhesion force was reversible and reproducible.

$\mathrm{CH}_{3}$ Interaction with K-Feldspar. To test for the effects of hydrophobicity as a function of salinity, we mapped the exact same spots that had been probed with the $-\mathrm{COO}(\mathrm{H})$ tip (Figure 5) with the hydrophobic, $-\mathrm{CH}_{3}$, tip (Figure 7), both in

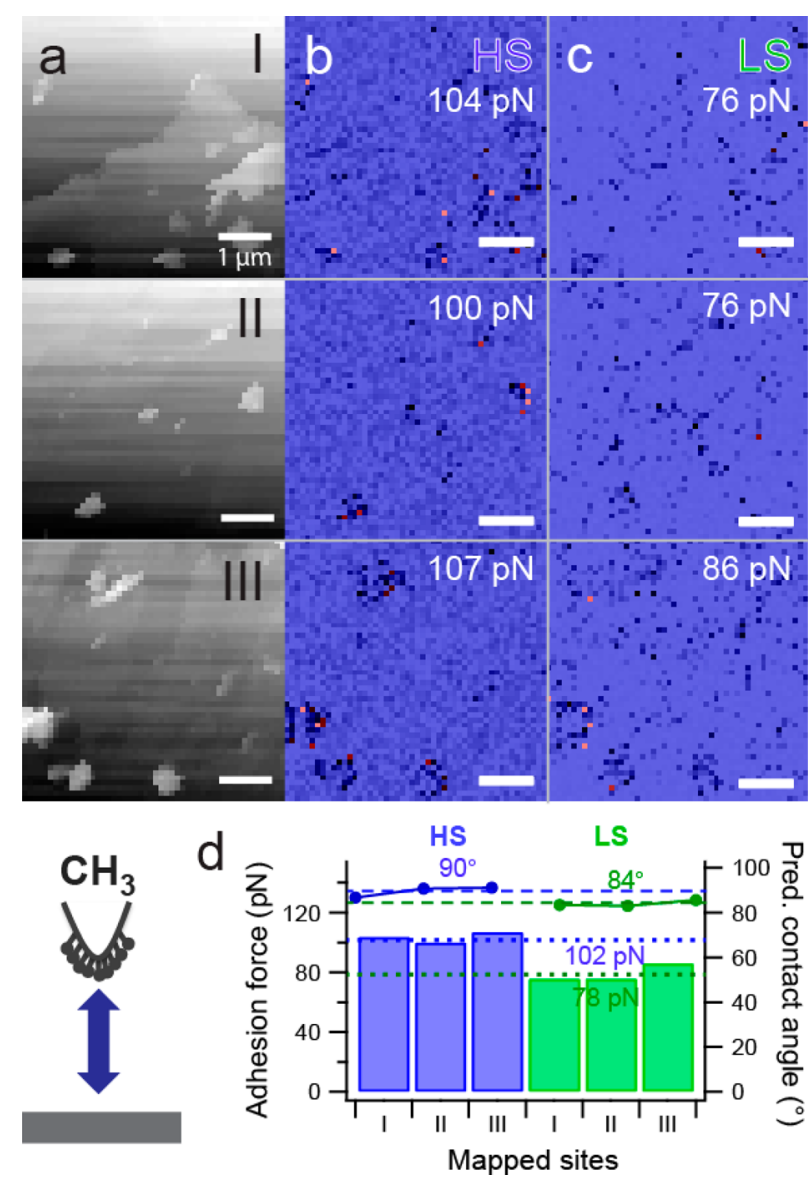

Figure 7. Adhesion response of the $-\mathrm{CH}_{3}$ tip to the $\mathrm{K}$-feldspar surface as a function of salinity and the contact angle determined with the Young-Dupré equation (eq 1). (a) The same sites shown in Figure 5 were mapped both in (b) HS and in (c) LS solutions. (d) The average adhesion force (dotted lines) was $\sim 23 \%$ lower when HS was replaced by LS. The contact angles determined from the total work of adhesion between hydrophobic tip and the surface (dashed lines) were on average $6^{\circ}$ higher in HS than in LS. The color code is the same as in Figure 5 .

HS (Figure 7b) and in LS (Figure 7c). In this setup, the overall adhesion force averaged over all curves was $23 \%$ lower in LS $(78 \mathrm{pN})$ as compared to HS (102 pN). Typical adhesion force between the $-\mathrm{CH}_{3}$ tip and the K-feldspar surface in high salinity conditions lies well below the level of the adhesion force for $-\mathrm{COO}(\mathrm{H})$ on $\mathrm{K}$-feldspar (Figures 5 and 6). The force distribution is also narrower, and the $90 \%$ quantile for the $-\mathrm{CH}_{3}$ interaction with $\mathrm{K}$-feldspar is at $135 \mathrm{pN}$ in $\mathrm{HS}$ (not shown) as compared to $303 \mathrm{pN}$ for the $-\mathrm{COO}(\mathrm{H})$ tip. Under 
LS conditions, the $90 \%$ quantile is $84 \mathrm{pN}$ for the $-\mathrm{CH}_{3}$ tip, as compared to $151 \mathrm{pN}$ for $-\mathrm{COO}(\mathrm{H})$. However, average adhesion forces for the two tips are comparable in LS solutions.

Contact Angles and Wettability. The contact angle, in this case the angle a water droplet forms on a solid in contact with a third immiscible fluid phase such as air or oil, is commonly used to describe the wettability of a surface. Surfaces are completely oil wet where the contact angle is $180^{\circ}$, completely water wet at $0^{\circ}$, and mixed wet near $90^{\circ}$. It is not possible to measure contact angle directly at the nanometer scale using traditional methods, which provide a macroscopic or average contact angle. However, using the Young-Dupré equation, we can estimate K-feldspar wettability by deriving contact angles from the total work of adhesion between the $-\mathrm{CH}_{3}$ tip and the K-feldspar surface. ${ }^{12,25}$ For site II (Figure 7), the contact angle determined with the Young-Dupré approach (dashed lines in Figure $7 \mathrm{~d}$ ) is $\sim 90^{\circ}$ in HS and $84^{\circ}$ in LS. A map of the contact angles determined from each of the individual force-distance curves provides more detail, but the average is in the same range (Figure 8). Because the absolute value for the
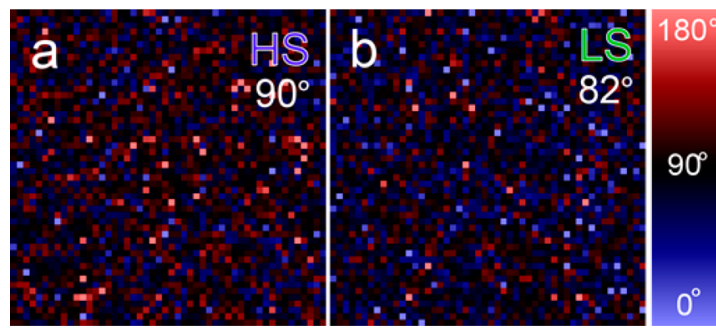

Figure 8. Nanoscale contact angle maps constructed from work of adhesion measured in HS (a) and LS (b). Each pixel represents one angle, determined from the individual force-distance curves for the response of the $-\mathrm{CH}_{3}$ tip to the K-feldspar surface at site II in Figure 7a. The surface is mixed wet at both salinity levels, but it is more hydrophilic (more blue) in LS. Maps for sites I and III (not shown) are similar. The maps are also $5 \times 5 \mu \mathrm{m}^{2}$.

contact angle cannot be calibrated, we used the change in contact angle between the HS and LS solutions for comparisons. For the data collected at site II (Figure 7d), $\Delta \theta_{\text {total }}=6^{\circ}$. The calculated contact angle shows that the Kfeldspar surfaces are mixed wet and they become more hydrophilic when high salinity solutions are replaced by low salinity, which is consistent with work reported by others. ${ }^{19,47}$ According to modeling by Sorbie, ${ }^{48}$ a difference in contact angle of $10^{\circ}$ is sufficient to trigger a low salinity effect that matches recovery rates observed in core plug tests.

Organic Material on the Mineral Surface. Previous work has demonstrated that adventitious carbon compounds have a significant effect on wettability, ${ }^{11,22}$ so we investigated how much and what type of organic material was adsorbed on the Kfeldspar surfaces. We used XPS to analyze the surface composition of two samples, a control that was only exposed to air and a second sample that was exposed to HS and LS to mimic the conditions of the CFM experiments. For the first sample, a freshly cleaved fragment was analyzed after exposure to air for $1 \mathrm{~h}$. The surface consisted of $\sim 5 \%$ carbon, which is equivalent to $\sim 0.3 \mathrm{~nm}$ if the carbon containing compound were spread in an even layer. When the first sample was analyzed again, after exposure to air for 30 days, $\sim 12 \%$ of the surface material was $\mathrm{C}$, meaning the equivalent thickness had about doubled $(0.7 \mathrm{~nm}$, Table 2$)$. The second sample was a freshly
Table 2. Atom Percent of Carbon in the Top $10 \mathrm{~nm}$ of the KFeldspar Surface, Estimated Equivalent C Layer Thickness, and Fraction of $\mathrm{C}-\mathrm{H} / \mathrm{C}-\mathrm{C}$ Bonds, Determined Using XPS

\begin{tabular}{|c|c|c|c|}
\hline exposure to & $\begin{array}{c}\text { proportion } \\
\text { of carbon } \\
{[\%]}\end{array}$ & $\begin{array}{l}\text { estimated } \\
\text { thickness of } \\
\text { the C layer } \\
{[\mathrm{nm}]}\end{array}$ & $\begin{array}{c}\text { proportion of }(\mathrm{C}-\mathrm{H} / \mathrm{C}-\mathrm{C}) \\
\text { bonds }[\%]\end{array}$ \\
\hline air for $1 \mathrm{~h}$ & 5 & 0.3 & 85 \\
\hline air for 30 days & 12 & 0.7 & 91 \\
\hline air + seawater & 13 & 0.8 & 85 \\
\hline
\end{tabular}

cleaved fragment that was exposed to air for $1 \mathrm{~h}$, to HS for 4.5 $h$, and rinsed with LS. A significant amount of adventitious carbon adsorbed from the solutions even though utmost care was taken to use ultrapure water and clean glass vessels. Solutions in nature contain far more carbon containing compounds. The atom percent of $\mathrm{C}$ on the water exposed sample was $\sim 13 \%$, which would produce an equivalent hydrocarbon layer thickness of $\sim 0.8 \mathrm{~nm}$. Considering a typical $\mathrm{C}-\mathrm{C}$ bond length of about $1.5 \AA(0.15 \mathrm{~nm})$, and assuming that all of the carbon is on the surface of the feldspar rather than buried within the top $10 \mathrm{~nm}$, one can conclude that this is a considerable amount of organic material, 6 or 7 equivalent layers, assuming the molecules are lying parallel to the surface.

Evidence from high-resolution infrared spectroscopy of particles from chalk shows patchy areas of hydrocarbons that vary in thickness and extent. ${ }^{49}$ Indirect evidence from elasticity and adhesion force measurements of what is presumed to be organic material on chalk also suggests that coverage is patchy. ${ }^{25}$ Whether the adsorbed carbon compounds on the feldspar completely cover the mineral surface or they exist in patchy areas, the adsorbed molecules would serve as anchor points for other organic compounds, such as our functionalized tips or molecules in oil, thus changing the adhesion forces of the surface. To assess how hydrophobic the K-feldspar surfaces were, we determined the relative proportion of nonpolar bonds, $\mathrm{C}-\mathrm{H}$ and $\mathrm{C}-\mathrm{C}$, using XPS (Table 2).

Quantity of Nonpolar Compounds in the Adsorbed Organic Material. For the three representative samples, the proportion of $\mathrm{C}-\mathrm{C}$ bonds in the organic material ranged from $85 \%$ to $91 \%$ (uncertainty in XPS is about $10 \%$ ). This quantity agrees well with DFT predictions of the relative composition at the interface of a typical crude oil with water. ${ }^{43} \mathrm{~A}$ mixture of polar and nonpolar organic molecules on the K-feldspar surface, and the possibility that patchiness leaves some of the mineral surface with minimal coverage, helps to explain the mixed wet character of the surface.

Comparison of Interactions of $-\mathrm{COO}(\mathrm{H})$ and $-\mathrm{CH}_{3}$ with K-Feldspar. The salinity-dependent changes in adhesion force that were observed for the interaction of $-\mathrm{COO}(\mathrm{H})$ with $\mathrm{K}$-feldspar were much more pronounced than those for the interaction of $\mathrm{CH}_{3}$ with $\mathrm{K}$-feldspar (Figure 9). Adhesion force in high salinity artificial seawater was $\sim 50 \%$ lower for the $-\mathrm{CH}_{3}$ tip than for the $-\mathrm{COO}(\mathrm{H})$ tip (Figure 9a, blue shaded area), which could be an indication that divalent ions promote the retention of polar molecules on mineral surfaces. ${ }^{50,51}$ In low salinity artificial seawater, adhesion forces were similarly low for both types of tips (Figure 9a, right set of data points, green area). Pooling all data collected in this study confirms this trend and shows that adhesion force is spread more for the $-\mathrm{COO}(\mathrm{H})$ interaction with K-feldspar (Figure 9b) than for the $-\mathrm{CH}_{3}$ interaction (Figure 9c), which indicates that more 

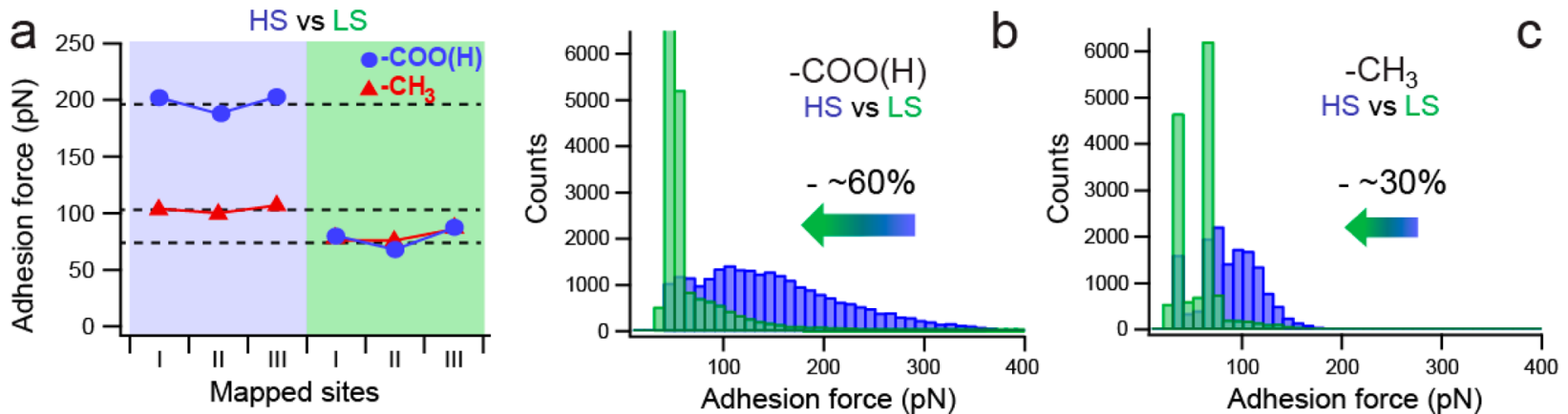

Figure 9. Salinity dependence of adhesion force between the functionalized tips and the K-feldspar surface. (a) In HS (left side of plot, blue field), the average adhesion force between $-\mathrm{COO}(\mathrm{H})$ tip and K-feldspar surface (blue dots) was significantly higher than that for the $-\mathrm{CH}_{3}$ tip (red $\mathbf{\Delta}$ ). In LS (right side of plot, green field), the average adhesion force for both types of tip was the same magnitude and lower than the force measured in HS. $(\mathrm{b}, \mathrm{c})$ Adhesion distribution of data pooled for all three mapped sites shows that $(\mathrm{b})$ the adhesion force between the $-\mathrm{COO}(\mathrm{H})$ tip and $\mathrm{K}$-feldspar spread over a range of $\sim 400 \mathrm{pN}$ (bin width: $10 \mathrm{pN}$ ), whereas (c) the distribution is significantly narrower for the $-\mathrm{CH}_{3}$ tip. When salinity decreases, the average adhesion force decreases by $\sim 60 \%$ with the $-\mathrm{COO}(\mathrm{H})$ tip and by $\sim 30 \%$ with the $-\mathrm{CH}_{3}$ tip, and the spread also decreases. It is important to remember that the histograms do not show measurement uncertainty. They represent the heterogeneity in the actual adhesion behavior at each sampled site. From this, we can interpret that surface composition is heterogeneous, even on this freshly cleaved mineral surface. The peaks near $50 \mathrm{pN}$ arise from hydrodynamic drag on the cantilever and represent an artifact.

than one mechanism of adsorption plays a role in the $-\mathrm{COO}(\mathrm{H})$ tip-surface interaction.

Molecular Basis for the Interaction of Functional Groups with K-Feldspar. To explore feldspar wettability at a molecular level, we estimated the impact of salinity and surface composition on tip-feldspar adhesion forces using molecular modeling with DFT. On the basis of relationships found in the literature, ${ }^{33,52}$ we express the total adhesion force measured between AFM tips and a feldspar surface $F_{\text {tot }}$ as

$$
F_{\text {tot }}=F_{\text {adh }}+F_{\text {edl }}
$$

where $F_{\text {adh }}$ represents the adhesion contribution that originates from the forces associated with surface composition, such as van der Waals interactions, hydrophobic interactions, hydration forces, and ion bridging. $F_{\text {edl }}$ represents the repulsive contribution resulting from electric double layer expansion.

Interactions between a $-\mathrm{COO}(\mathrm{H})$ Tip and a Surface. The $-\mathrm{CH}_{3}$ is assumed neutral, but the $-\mathrm{COO}(\mathrm{H})$ tip can be charged, depending on ionic strength and $\mathrm{pH}$. Bridging by cations between the $-\mathrm{COO}^{-}$tip and the surface can influence the composition and charge, which could modify properties and behavior of both the tip and the surface. With the COSMO-RS implicit solvent model, we explored the tendencies for ion bridging between tip and surface. We used the difference in chemical potentials between a cation carrying tip, $-\mathrm{COO}-\mathrm{M}$, where $\mathrm{M}=\mathrm{Ca}^{2+}$ or $\mathrm{Mg}^{2+}$, and a protonated tip, $-\mathrm{COOH}$. Thus, from $\Delta \Delta \mu(\mathrm{S})$ determined using eq 2 , we could estimate how favorable the formation of $\mathrm{Ca}^{2+}$ or $\mathrm{Mg}^{2+}$ mediated ion bridges would be. In our model, ion bridging takes place if $\Delta \Delta \mu$ $<0$, that is, if the adhesion of $-\mathrm{COO}-\mathrm{M}$ to the surface is stronger than the adhesion of $-\mathrm{COOH}$. We distinguished between the two pure mineral surface sites, $\mathrm{Si}(\mathrm{OH})_{4}$ and $\mathrm{Si}(\mathrm{OH})_{3}{ }^{-}$, and several types of organic compounds, which are listed in Table 1. Our calculations indicate that $\mathrm{Ca}^{2+}$ - and $\mathrm{Mg}^{2+}$ mediated ion bridging only takes place between the $-\mathrm{COO}(\mathrm{H})$ tip and the negatively charged sites, that is, $\mathrm{Si}(\mathrm{OH})_{3} \mathrm{O}^{-}$, for the pure mineral surface sites and benzoate, representing the adsorbed organic material.

To estimate the contribution of ion bridging to the total adhesion force, $F_{\text {adh }}$, measured between a $-\mathrm{COO}(\mathrm{H})$ tip and the mineral surface at high and low salinity, we estimated surface charge by using the degree of protonation for the
$-\mathrm{COO}(\mathrm{H})$ moieties. DFT predicts that, of the seawater cations, $\mathrm{Mg}^{2+}$ binds most strongly to the fully deprotonated model dimer $\left(\Delta G_{\text {ads,double }}=-18.4 \mathrm{~kJ} / \mathrm{mol}\right.$, Table 3$)$. We predict

Table 3. Predicted Free Energy of the Seawater Cations (According to Reactions Ia, Ib, IIa, and IIb) Adsorbing to a Singly and Doubly Deprotonated Octanoate Dimer and Ion Coverage of the Surface on the -COOH-Functionalized AFM Tip in HS and $\mathrm{LS}^{a}$

$\begin{array}{lcccc}\text { ion } & \begin{array}{ccc}\Delta G_{\text {adssingle }} \\ {[\mathrm{kJ} / \mathrm{mol}]}\end{array} & \begin{array}{c}\Delta G_{\text {ads,double }} \\ {[\mathrm{kJ} / \mathrm{mol}]}\end{array} & \begin{array}{c}\text { coverage } \\ \mathrm{HS}\end{array} & \begin{array}{c}\text { coverage } \\ \text { LS }\end{array} \\ \mathrm{Na}^{+} & 32.3 & 27.7 & 0.00 & 0.00 \\ \mathrm{~K}^{+} & 40.6 & 51.4 & 0.00 & 0.00 \\ \mathrm{Ca}^{2+} & 27.1 & -2.6 & 0.00 & 0.00 \\ \mathrm{Mg}^{2+} & 1.9 & -18.4 & 0.99 & 0.77\end{array}$

${ }^{a}$ According to our calculations, $\mathrm{Mg}^{2+}$ ions bind most strongly to the doubly deprotonated dimer, whereas $\mathrm{Na}^{+}, \mathrm{K}^{+}$, and $\mathrm{Ca}^{2+}$ ions are outcompeted. Surface coverage by $\mathrm{Mg}^{2+}$ ions is $22 \%$ lower in LS than in HS. Details in note S10.

that the coverage of the tip with $\mathrm{Mg}^{2+}$ ions would be $\sim 77 \%$ in LS solutions, in contrast with $99 \%$ in HS, which was determined using a Langmuir isotherm for competitive adsorption of all ions. This means that the ion bridging capacity of the tip decreases by $22 \%$ in low salinity solutions. With an estimated contact area of $365 \mathrm{~nm}^{2}$ between the tip and the sample and an estimated surface charge of $\sigma_{\mathrm{S}}=-0.015 \mathrm{C} /$ $\mathrm{m}^{2,9,25}$ we approximated the number of ion bridges to be 34 . If all bridging is by $\mathrm{Mg}^{2+}$, this gives a total energy of $34 \times-5.3$ $\mathrm{kJ} / \mathrm{mol}=-180 \mathrm{~kJ} / \mathrm{mol}$ (Table 1 ), which amounts to a surface energy of $0.82 \mathrm{~mJ} / \mathrm{m}^{2}$. The change in surface energy for the whole tip is then scaled by $22 \%$, corresponding to the part of the surface that releases divalent ions in LS. We next used JKR (Johnson-Kendall-Roberts) theory to relate the change in surface energy, $\Delta W=0.22 \times 0.82 \mathrm{~mJ} / \mathrm{m}^{2}$, to a change in adhesion force: ${ }^{33,52,53}$

$$
\Delta F_{\text {adh(ion) }}=3 / 2 \pi R \Delta W
$$

where the tip radius, $R$, is $30 \mathrm{~nm}$. This produces a drop in adhesion force of $27 \mathrm{pN}$ when LS replaces $\mathrm{HS}$ as a consequence of reduced ion bridging capacity at low concentrations of 
divalent ions. The energy difference is significant but not large enough to explain the large decrease in adhesion force between $-\mathrm{COO}(\mathrm{H})$ and K-feldspar $(\sim 130 \mathrm{pN}$, Figure $9 \mathrm{a})$ when HS was replaced by $\mathrm{LS}$. If $\mathrm{Ca}^{2+}$ bonded to the tip instead of $\mathrm{Mg}^{2+}$, the effect of ion bridging would be greater by a factor of 5 (Table 1 ), which would make the change in adhesion force between HS and LS comparable to experiments. However, our calculations predict that $\mathrm{Mg}^{2+}$ is favored over $\mathrm{Ca}^{2+}$, and we must interpret our results consistently using the same model. We assume that van der Waals and hydrophobic interactions are negligible in the case of the $-\mathrm{COO}(\mathrm{H})$ tip and focus on the contribution of electric double layer forces.

Electric double layer repulsion depends strongly on salinity and surface charge for both tip and substrate. We estimated the contribution of the electric double layer by using an expression from Butt and co-workers: ${ }^{52}$

$$
F_{\text {edl }}=\frac{2 \pi R \lambda_{\mathrm{D}}}{\varepsilon \varepsilon_{0}}\left[2 \sigma_{\mathrm{S}} \sigma_{\mathrm{T}} \mathrm{e}^{-D / \lambda_{\mathrm{D}}}+\left(\sigma_{\mathrm{S}}^{2}+\sigma_{\mathrm{T}}^{2}\right) \mathrm{e}^{-2 D / \lambda_{\mathrm{D}}}\right]
$$

where $\lambda_{\mathrm{D}}$ represents the Debye length, $\varepsilon$ is the dielectric constant of the medium, $\varepsilon_{0}$ is the vacuum permittivity, and $\sigma_{\mathrm{S} / \mathrm{T}}$ is the surface charge densities of surface and tip. To account for the impact of additional charge on electric double layer repulsion, we need to estimate the fraction of deprotonated acid groups in a $-\mathrm{COO}(\mathrm{H}) \mathrm{SAM}$.

Influence of the Change in Surface Charge on the AFM Tip. We estimated the fraction of deprotonated acid groups in a $-\mathrm{COO}(\mathrm{H})$ SAM at a range of salinities, by using the analytical formula proposed by Olsson et al.: ${ }^{54}$

$$
\Delta G=2.3 R T \theta\left(\mathrm{pK}_{\mathrm{a}}^{\mathrm{int}}-\mathrm{pH}\right)+\frac{996 \theta}{\varepsilon \frac{a}{\sqrt{\theta}}\left(\frac{a}{\mathrm{e}^{\lambda} D \sqrt{\theta}-1}\right)}
$$

$$
-R T \theta \log (\theta)
$$

where $\theta$ represents the deprotonated fraction and $a$ is the distance between molecules in the $2 \mathrm{D}$ layer, that is, the lattice parameter $(5.0 \AA)$ for a $-\mathrm{COO}(\mathrm{H})$ terminated SAM that has hexagonal symmetry. The first $\mathrm{p} K_{\mathrm{a}}$ for deprotonating a $-\mathrm{COO}(\mathrm{H}) \mathrm{SAM}$, which is valid for low deprotonated fractions, is $4.7 .^{43}$ When $\Delta G$ in eq 6 is minimized, using a Debye length of $2 \mathrm{~nm}$, which would be the case at the ionic strength of LS, the deprotonated fraction is $8.7 \%$. If we combine the deprotonated fraction with the area of the SAM unit cell, we find that surface charge density is predicted to be $-0.056 \mathrm{C} / \mathrm{m}^{2}$. On our tip, only $23 \%$ of the surface is able to deprotonate because $77 \%$ was predicted to be covered by $\mathrm{Mg}^{2+}$, which inhibits $-\mathrm{COO}(\mathrm{H})$ deprotonation so the surface charge for the $-\mathrm{COO}(\mathrm{H})$ tip in low salinity water is $23 \% \times-0.056 \mathrm{C} / \mathrm{m}^{2}=$ $-0.013 \mathrm{C} / \mathrm{m}^{2}$.

We used eq 5 to estimate the electric double layer repulsion forces. On quartz grains, ${ }^{9}$ we determined $D=1.0 \mathrm{~nm}$ and $\sigma_{\mathrm{S}}=$ $-0.015 \mathrm{C} / \mathrm{m}^{2}$. Because of the structural similarity of quartz and feldspar surfaces, we assumed that $D$ and $\sigma_{\mathrm{S}}$ are similar for feldspar. Our assumption of equal surface charge is further justified by similar $\mathrm{pH}_{\mathrm{pzc}}$ (points of zero charge) ${ }^{46}$ and similar zeta potential for microcline and quartz, measured at $\mathrm{pH}=8$ in low salinity artificial seawater. ${ }^{55}$ With $\sigma_{\mathrm{T}}=-0.013 \mathrm{C} / \mathrm{m}^{2}$, the drop in adhesion force was $140 \mathrm{pN}$, when LS replaced HS. This is a result of electric double layer expansion. ${ }^{9}$ This is, with or without the contribution of ion bridging, in excellent agreement with the experimentally determined difference in adhesion forces between the $-\mathrm{COO}(\mathrm{H})$ tip in high salinity as compared to low salinity (Figure 9, Table 4). Hence, we can conclude that the contribution from the electric double layer is high as compared to the contribution from ion bridging.

Table 4. Comparison of Experimental Mean Values of Adhesion Force with Estimated Theoretical Contributions for the $-\operatorname{COO}(\mathrm{H}) \mathrm{Tip}$

\begin{tabular}{lc}
\multicolumn{3}{c}{$-\mathrm{COO}(\mathrm{H})$} \\
\hline \multicolumn{2}{c}{$\begin{array}{c}\text { experimental mean values of adhesion } \\
\text { force }\end{array}$} \\
HS $194 \mathrm{pN} \quad \Delta F_{\mathrm{HS} / \mathrm{LS}}=118 \mathrm{pN}$ & $\Delta F_{\text {Ion bridging }}=27 \mathrm{pN}$ \\
LS $76 \mathrm{pN}$ & $\Delta F_{\text {edl }}=140 \mathrm{pN}$ \\
\hline
\end{tabular}

Interactions between a $-\mathrm{CH}_{3}$ Tip and the Mineral Surface. For the interactions with the $-\mathrm{CH}_{3}$ tip, the drop in adhesion when salinity decreases $(\sim 25 \mathrm{pN}$; Figure 7 , Table 5$)$

Table 5. Comparison of Experimental Mean Values of

\begin{tabular}{|c|c|}
\hline \multicolumn{2}{|c|}{$-\mathrm{CH}_{3}$} \\
\hline $\begin{array}{l}\text { experimental mean values of adhesion } \\
\text { force }\end{array}$ & estimated theoretical contributions \\
\hline $\begin{array}{l}\mathrm{HS} 102 \mathrm{pN} \\
\mathrm{LS} 78 \mathrm{pN}\end{array}$ & $\Delta F_{\text {edl }}=28 \mathrm{pN}$ \\
\hline
\end{tabular}
Adhesion Force to Estimated Theoretical Contributions for the $-\mathrm{CH}_{3}$ Tip

is very similar in magnitude to what we measured on quartz grains from sandstone., ${ }^{9,56}$ The strong similarity found between natural quartz and the pure mineral samples of K-feldspar, for both surface charge and the salinity-dependent change in adhesion determined using the same tip composition, suggests that electric double layer expansion is the dominant contribution to the decrease in adhesion force between a $-\mathrm{CH}_{3}$ tip and the K-feldspar surface when $\mathrm{HS}$ is replaced by LS. In low salinity solution, only the electric double layer on the mineral surface can exert a repulsive force on the tip. Using eq 4 , with a tip charge of $0, D=1 \mathrm{~nm}$, and $\sigma_{\mathrm{S}}=-0.015 \mathrm{C} / \mathrm{m}^{2}$, we calculated an electric double layer repulsion contribution of 28 $\mathrm{pN}$ (Table 5), which corresponds to $20 \%$ of the repulsive force estimated for the $-\mathrm{COO}(\mathrm{H})$ tip-surface interaction in low salinity conditions. Hence, one could expect the measured adhesion forces between a $-\mathrm{CH}_{3}$ tip and the surface in low salinity conditions to be higher than for the $-\mathrm{COO}(\mathrm{H})$ tip. However, Figure 9a shows that the magnitude of adhesion force in low salinity solutions is comparable for the two types of tip; this might be caused by another repulsive contribution between the $-\mathrm{CH}_{3}$ tip and the mineral surface or by less attractive force than for the $-\mathrm{COO}(\mathrm{H})$ tip-mineral interaction. Because the $-\mathrm{CH}_{3}$ tip is neutral, the contribution of ion bridging between the mineral surface and the tip is zero. Hence, similar adhesion force for both types of tip is evidence against ion bridging between the $-\mathrm{CH}_{3}$ tip and the mineral surface. For the $-\mathrm{CH}_{3}$ tip in high salinity solution, the electric double layer is collapsed and ion bridging is excluded. Therefore, the measured adhesion force between the $-\mathrm{CH}_{3}$ tip and the substrate must originate from van der Waals forces and the hydrophobic interactions, which most likely involves the nonpolar material we detected with XPS (Table 2).

Our calculations give a very reasonable explanation for the difference in low salinity response of the two types of tip. At high salinity, cation adsorption leads to charge neutralization on 
the $-\operatorname{COO}(\mathrm{H})$ tip (Table 1$)$, which allows for ion bridging between tip and sample. At low salinity, ion bridging becomes less likely because of the significantly reduced coverage by divalent ions. Our assessment for the molecular scale interactions between oil components and the K-feldspar surface is (i) although ion bridging might dominate the molecular scale interaction between polar components and the K-feldspar surface at high salinity conditions, the decrease in adhesion force as salinity decreases results from increased electric double layer repulsion, and (ii) the interaction between nonpolar components and the K-feldspar surface is controlled by hydrophobic interactions with organic material adsorbed on the feldspar. However, in low salinity conditions, adhesion force decreases because of the repulsive effect of the mineral surface electric double layer. The high electric double layer repulsion resulting from surface charge on the tip is the main reason for the difference in behavior of the two tip types.

Relative Influence of $\mathrm{Mg}^{2+}$ and $\mathrm{Ca}^{2+}$. Our calculations predict that $\mathrm{Mg}^{2+}$ associates strongly with the tip, whereas, most commonly, $\mathrm{Ca}^{2+}$ is assumed to be the most important ion for the low salinity effect. Currently, we do not have enough experimental or computational data to definitively say that one or the other ion is more important. The difference between monovalent and divalent ions is clear, but uncertainties in the theoretical models make us unable to draw conclusions about the relative influence of $\mathrm{Mg}^{2+}$ versus $\mathrm{Ca}^{2+}$. Our model of the tip is a very small model, and the divalent ions have significant and different deviations in the experimental hydration energies using COSMO-RS. ${ }^{44}$ There are conflicting results in the literature, as well. Some authors argue that $\mathrm{Mg}^{2+}$ binding to carboxylate is weak because of its strong hydration, ${ }^{57,58}$ while measurements of the interfacial tension between oil and water, in the presence of carboxylic acids and divalent ions, led to virtually identical results for $\mathrm{Mg}^{2+}$ and $\mathrm{Ca}^{2+}, 59$ and significantly different for $\mathrm{Na}^{+}$. This indicates that binding of $\mathrm{Mg}^{2+}$ and $\mathrm{Ca}^{2+}$ to carboxylate is very similar, and different from monovalent ions.

\section{CONCLUSIONS}

The K-feldspar surfaces were chemically probed with nonpolar $\left(-\mathrm{CH}_{3}\right.$ terminated $)$ and polar $(-\mathrm{COO}(\mathrm{H})$ terminated $)$ tips, as a function of salinity, to measure adhesion forces and to gain insight into the behavior of feldspar surfaces in oil reservoirs. We observed a salinity-dependent change in adhesion between the K-feldspar surface and both types of tip, which corresponds to a salinity-dependent wettability conversion of the mineral surface. K-feldspar becomes more hydrophilic in low salinity solutions. The decrease in adhesion is more pronounced for interaction with the polar functional group $(\sim 60 \%)$ than for the hydrophobic group $(\sim 30 \%)$. In the high salinity conditions used in this study, the acidic oil model component adheres more strongly to the K-feldspar surface than does the hydrophobic model component, whereas in low salinity solutions, both types adhere to the same extent.

We observed adventitious organic material on the K-feldspar surface, even when it had been freshly cleaved. This hydrocarbon, which adsorbs spontaneously from air and solutions, changes the surface composition, thus changing surface free energy, and could provide anchors for adsorption of the nonpolar tip. Our results indicate that increased electric double layer repulsion is the main contributor to the salinity dependence of the model oil components on feldspar surfaces. Ion bridging probably strengthens the interaction between polar components and the silicate mineral surface, but it plays a smaller role than the electric double layer effects. Our work also reconfirms that wettability is not an intrinsic property of the solid. It depends on the type of oil and the composition of the aqueous solution that is in contact with the rock, as well as the composition of the solid surface, that is, the type and amount of adventitious organic material.

\section{ASSOCIATED CONTENT}

\section{S Supporting Information}

The Supporting Information is available free of charge on the ACS Publications website at DOI: 10.1021/acs.energyfuels.6b02969.

Additional computational data, as well as XRD, XPS, and EDXS data (PDF)

\section{AUTHOR INFORMATION}

\section{Corresponding Authors}

*E-mail: blorenz@nano.ku.dk.

*E-mail: tue@nano.ku.dk.

ORCID ()

B. Lorenz: 0000-0001-5085-0183

M. Ceccato: 0000-0002-6653-836X

M. P. Andersson: 0000-0002-4921-1461

Notes

The authors declare no competing financial interest.

\section{ACKNOWLEDGMENTS}

We thank T. Balic-Zunic from the Museum of Natural History for discussions and help with the XRD analysis and the members of the NanoGeoScience group, especially J. Matthiesen, for discussion, help with analyses, data interpretation, and critique on the manuscript. We are grateful for very useful comments from two anonymous reviewers. This work is part of the Nano-Sand Project, funded by the BP Exploration Operating Co. Ltd., under the Enhanced Oil Recovery Technology Flagship ExploRe Programme.

\section{NOMENCLATURE}

$\mathrm{AFM}=$ atomic force microscopy

ASW $=$ artificial seawater

$\mathrm{CFM}=$ chemical force microscopy

DFT $=$ density functional theory

EDXS = electron-dispersive X-ray spectroscopy

HS = high salinity solution

LS = low salinity solution

SAM $=$ self-assembled monolayer

SEM = scanning electron microscopy

$\mathrm{XPS}=\mathrm{X}$-ray photoelectron spectroscopy

$\mathrm{XRD}=\mathrm{X}$-ray diffraction

\section{REFERENCES}

(1) Morrow, N. R.; Tang, G. Q.; Valat, M.; Xie, X. J. Pet. Sci. Eng. 1998, 20, 267-276.

(2) Webb, K. J.; Black, C. J. J.; Al-Ajeel, H. SPE 81460, 2003.

(3) Lager, A.; Webb, K. J.; Collins, I. R.; Richmond, D. M. SPE 113976, 2008

(4) Tang, G. Q.; Morrow, N. R. J. Pet. Sci. Eng. 1999, 24, 99-111.

(5) Seccombe, J.; Lager, A.; Jerauld, G.; Jhaveri, B.; Buikema, T.; Bassler, S.; Denis, J.; Webb, K. J.; Cockin, A.; Fueg, E. SPE 129692, 2010.

(6) Sheng, J. J. J. Pet. Sci. Eng. 2014, 120, 216-224. 
(7) Shabib-Asl, A.; Ayoub, M. A.; Elraies, K. A. SPE 176492, 2015.

(8) Lager, A.; Webb, K. J.; Black, C. J. J. 14th Eur. Symp. on Improved Oil Recovery, Egypt, 2007.

(9) Hilner, E.; Andersson, M. P.; Hassenkam, T.; Matthiesen, J.; Salino, P. A.; Stipp, S. L. S. Sci. Rep. 2015, 5, 9933.

(10) McGuire, P. L.; Chatham, J. R; Paskvan, F. K.; Sommer, D. M.; Carini, F. H. SPE 93903, 2005.

(11) Hassenkam, T.; Mitchell, A. C.; Pedersen, C. S.; Skovbjerg, L. L.; Bovet, N.; Stipp, S. L. S. Colloids Surf., A 2012, 403, 79-86.

(12) Drummond, C.; Israelachvili, J. J. Pet. Sci. Eng. 2004, 45, 61-81.

(13) Hassenkam, T.; Pedersen, C. S.; Dalby, K.; Austad, T.; Stipp, S.

L. S. Colloids Surf., A 2011, 390, 179-188.

(14) Austad, T.; Rezaeidoust, A.; Puntervold, T. SPE 129767, 2010.

(15) Kumar, M.; Fogden, A.; Senden, T.; Knackstedt, M. SPE 129974, 2010.

(16) Vledder, P.; Carrera Fonseca, J.; Wells, T.; Gonzalez, I.; Ligthelm, D. SPE 129564, 2010.

(17) Sandengen, K.; Tweheyo, M. T.; Raphaug, M.; Kjølhamar, A.; Crescente, C.; Kippe, V. Int. Symp. of Society of Core Analysts; Statoil: Austin, TX, 2011.

(18) Nasralla, R. A.; Nasr-El-Din, H. A. SPE 154334, 2014.

(19) Ligthelm, D.; Gronsveld, J.; Hofman, J.; Brussee, N.; Marcelis, F.; Linde, H. v. d. SPE 119835, 2009.

(20) Lager, A.; Webb, K. J.; Black, C. J. J.; Singleton, M.; Sorbie, K. S. Petrophysics 2008, 49, 28-35.

(21) Strand, S.; Austad, T.; Puntervold, T.; Aksulu, H.; Haaland, B.; RezaeiDoust, A. Energy Fuels 2014, 28, 2378-2383.

(22) Matthiesen, J.; Bovet, N.; Hilner, E.; Andersson, M. P.; Schmidt, D. A.; Webb, K. J.; Dalby, K. N.; Hassenkam, T.; Crouch, J.; Collins, I. R.; Stipp, S. L. S. Energy Fuels 2015, 28, 4849-4858.

(23) Frisbie, C. D.; Rozsnyai, L. F.; Noy, A.; Wrighton, M. S.; Lieber, C. M. Science 1994, 265, 2071-2074.

(24) Noy, A.; Frisbie, C. D.; Rozsnyai, L. F.; Wrighton, M. S.; Lieber, C. M. J. Am. Chem. Soc. 1995, 117, 7943-7951.

(25) Hassenkam, T.; Skovbjerg, L. L.; Stipp, S. L. S. Proc. Natl. Acad. Sci. U. S. A. 2009, 106, 6071-6076.

(26) Patterson, A. L. Phys. Rev. 1939, 56, 978-982.

(27) Coelho, A. J. Appl. Crystallogr. 2003, 36, 86-95.

(28) Barr, T. L.; Seal, S. J. Vac. Sci. Technol., A 1995, 13, 1239-1246.

(29) Noy, A. Surf. Interface Anal. 2006, 38, 1429-1441.

(30) He, H.-X.; Huang, W.; Zhang, H.; Li, Q. G.; Li, S. F. Y.; Liu, Z. F. Langmuir 1999, 16, 517-521.

(31) Hutter, J. L.; Bechhoefer, J. Rev. Sci. Instrum. 1993, 64, 18681873.

(32) Butt, H. J.; Jaschke, M. Nanotechnology 1995, 6, 1.

(33) Israelachvili, J. N. Intermolecular and Surface Forces, 3rd ed.; Elsevier Inc.: Waltham, MA, 2011.

(34) Aveyard, R.; Haydon, D. A. Trans. Faraday Soc. 1965, 61, 22552261.

(35) Wu, D.; Hornof, V. Chem. Eng. Commun. 1999, 172, 85-106.

(36) Ahlrichs, R.; Bär, M.; Häser, M.; Horn, H.; Kölmel, C. Chem. Phys. Lett. 1989, 162, 165-169.

(37) Becke, A. D. Phys. Rev. A: At., Mol., Opt. Phys. 1988, 38, 30983100

(38) Perdew, J. P. Phys. Rev. B: Condens. Matter Mater. Phys. 1986, 33, $8822-8824$.

(39) Schäfer, A.; Horn, H.; Ahlrichs, R. J. Chem. Phys. 1992, 97, 2571-2577.

(40) Klamt, A.; Schuurmann, G. J. Chem. Soc., Perkin Trans. 2 1993, 799-805.

(41) Klamt, A.; Eckert, F.; Arlt, W. Annu. Rev. Chem. Biomol. Eng. 2010, 1, 101-122.

(42) Eckert, F.; Klamt, A. COSMOtherm, 13.01 ed.; COSMOlogic GmbH \& Co. KG: Leverkusen, Germany, 2013.

(43) Andersson, M. P.; Olsson, M. H. M.; Stipp, S. L. S. Langmuir 2014, 30, 6437-6445.

(44) Andersson, M. P.; Stipp, S. L. S. J. Comput. Chem. 2014, 35, $2070-2075$.

(45) DeVore, G. W. Clays Clay Miner. 1957, 6, 26-41.
(46) Kosmulski, M. Surface Charging and Points of Zero Charge; CRC Press, Taylor \& Francis Group: New York, 2009; Vol. 145.

(47) Pedersen, N. R.; Hassenkam, T.; Ceccato, M.; Dalby, K. N.; Mogensen, K.; Stipp, S. L. S. Energy Fuels 2016, 30, 3768-3775.

(48) Sorbie, K. S. SPE 129833, 2010.

(49) Andersson, M. P.; Hem, C. P.; Schultz, L. N.; Nielsen, J. W.; Pedersen, C. S.; Sand, K. K.; Okhrimenko, D. V.; Johnsson, A.; Stipp, S. L. S. J. Phys. Chem. A 2014, 118, 10720-10729.

(50) Theng, B. K. G. Clays Clay Miner. 1982, 30, 1-10.

(51) Arnarson, T. S.; Keil, R. G. Mar. Chem. 2000, 71, 309-320.

(52) Butt, H. J.; Cappella, B.; Kappl, M. Surf. Sci. Rep. 2005, 59, 1152.

(53) Johnson, K. L.; Kendall, K.; Roberts, A. D. Proc. R. Soc. London, Ser. A 1971, 324, 301-313.

(54) Olsson, M. H. M.; Andersson, M. P.; Matthiesen, J.; Pedersen, N.; Dobberschütz, S.; Hassenkam, T.; Stipp, S. L. S. Surface titration of ionisable weak acids in self assembled monolayers at high and low salinity; predictions and experiments. Manuscript in preparation.

(55) Shehata, A. M.; Nasr-El-Din, H. A. SPE 173763, 2015.

(56) Matthiesen, J.; Hassenkam, T.; Bovet, N.; Dalby, K.; Stipp, S. L. S. Energy Fuels 2017, 31, 55-64.

(57) Huynh, U. T. D.; Lerbret, A.; Neiers, F.; Chambin, O.; Assifaoui, A. J. Phys. Chem. B 2016, 120, 1021-1032.

(58) Okur, H. I.; Kherb, J.; Cremer, P. S. J. Am. Chem. Soc. 2013, 135, 5062-5067.

(59) Robertson, E. J.; Beaman, D. K.; Richmond, G. L. Langmuir 2013, 29, 15511-15520. 